\title{
Comentario de un poema de Federico García Lorca
}

\author{
Dieter Oelker
}

\author{
Universidad de Concepción
}

\begin{abstract}
Resumen
Las diversas fases operatorias del comentario de texto permiten comprender el poema "Caracola" del libro Canciones (1972) de Federico García Lorca, como una composición que trabaja para constituirse en un complejo signo de totalidad. La técnica para lograr ese propósito esla combinación de realidades heterogéneas, que permitemostrar lainterrelación delosfenómenosy su fundamental unidad. "Caracola" y "corazón" son los centros estructurales del texto. A partir de ellos se proyecta una alternancia de ritmos que envuelve el poema en una dinámica de expansión y recogimiento. En ella se disuelven los límites, de manera que la naturaleza y el hombre, lo material y lo espiritual, la circunstancia y el cosmosseintegran y participan de una misma pulsación universal. La utilización del montaje para develar en realidad empírica, dispersa y fragmentada, la existencia de una segunda realidad, señala la procedencia cubista y surreal ista de la composición. El poeta se vale de esa técnica para construir un poema que en el encuentro de elementos disímiles conforma una estructura estética no imitativa, que transparenta una realidad, no parcial ni fragmentada, sino total - pre-apariencia estética de la totalidad perdida cuya reconstitución apela a la libre actividad del lector.
\end{abstract}

Palabras Claves: Signo de totalidad, realidades heterogéneas, centros estructurales, alternancia rítmica, montaje, actividad del lector.

\section{ABst RACT}

The diverse operative phases of text commentary allow us to understand the poem "Caracola" from the book Canciones (1927) by Federico García Lorca, as a composition that strives to become a complex sign of total ity. The technique to achieve this intention is the combination of heterogeneous realities, which allows us to see the interrelationship of the phenomena and their fundamental unit. "C aracola" and "corazón" arethestructural centers of the text. From these centers an alternation of rhythms is projected that wraps the poem in that dynamics of expansion an retraction. In that alternation the limits are dissolved, so that nature and man, the material and the spiritual, the circumstance and the cosmos unite and share the same universal pulsation. The use of the montage to unveil in the empirical reality, dispersed and fragmented, the existense of a second reality, indicates the cubist and surreal istic origin of the composition. The poet uses thistechnique to construct 
a poem that in the gathering of dissimilar elements shapes an aesthetic, nom-imitative structure, which conveys a neither partial nor gragmented but whole reality - the aesthetic pre-appearance of the lost totality whose reconstitution appeals to the free endeavor of the reader.

KeYwords: Sign of totality, heterogeneous realities, structural centers, alternation of rhythms, montage, endeavor of the reader.

Recibido: 22.03.2003. Aceptado: 20.04.2003.

La lectura no es sólo contemplación sino desciframiento y crítica.

O ctavio Paz, Pasión crítica

\section{Caracola}

A N atalita Jiménez

M e han traído una caracola.

1 D entro le canta

2 un mar de mapa.

3 M i corazón

4 sellena de agua,

5 con pececillos

6 de sombra y plata.

M e han traído una caracola.

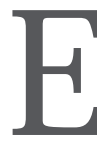

SPO SIBLE queen una primera lectura del poema "C aracola" reparemos, especialmente, en su particular disposición gráfica, es decir, en el hecho que su estrofa aparezca como ocupando un espacio abierto entre los límites quelefijan los estribillos. Estimamos que con ello se nos sugiere la idea de albergue y morada, que también expresa y aun refuerza la caracola en cuanto lugar que contiene el canto del mar, el corazón en cuanto recibe y lleva el agua y el agua en cuanto acoge los "pececillos de sombra y plata".

Sin embargo, igualmente nos puede sorprender el desarrollo del poema a partir de un hecho tan fortuito y cotidiano como lo es el regalo de una caracola. Esque el canto del mar que la habita, una vez escuchado, difluye y penetra en el 
corazón del receptor, sujeto de la enunciación. Pensamos, por eso, que los centros estructurantes del texto son caracola y corazón, relacionados y casi confundidos gracias al arrullo efuso del mar. No cabe duda que cada una de estas palabras claves deben ser consideradas como símbolos antes quesignos, y queel poema en su conjunto constituye un signo complejo de carácter simbólico.

Lo otro que posiblemente llame la atención es que el texto se encuentre conformado - más allá de todo principio imitativo- por la concurrencia de elementos del todo heterogéneos. En la realidad del poema interactúan componentes humanos, naturales, materiales y espirituales, de tal manera que cada elemento participa del otro en sugerencia de la unidad de lo diferente y presencia del todo en las partes de la totalidad.

Localizamos el poema en la sección "C anciones para niños" del libro Canciones, publicado en 1927, no obstante que en lo esencial fuera escrito entre 1921 y 1924. En consecuencia, el trabajo en esta obra coincidió con la composición de Suites (1920-1923), la publicación del Poema del Cante Jondo (1921) y la elaboración del Romancero gitano (1924-1927).

En el año de la aparición del libro Canciones se recuerda a García Lorca como de "gesto afectuoso, vehemente y enérgico, con intermitencias lánguidas. C arácter joven, fogoso, impulsivo - ampuloso y conciso a la par- de una imaginación vel osísima. Cada frase, una idea; cada palabra, un verso. Su conversación dejaba bien afirmada una individualidad violenta, salvaje, y al propio tiempo, alegre y fresca como el primer soplo de un viento que seinicia" (Gasch, 1950: 9).

L a poesía de G arcía Lorca ha sido caracterizada como "tradicional y novísima a un tiempo". En ella prevalecen los val ores musicales y, muy especialmente, el sentido del ritmo que en el poeta "al canza una variedad, una finura prodigiosas". Sin embargo, el ritmo es también arquitectura, porque "todos sus poemas están, con cálculo perfecto, construidos, muy sabiamente estructurados" (Guillén, en García Lorca, ${ }^{8} 1968:$ LIII y LIV).

Según su autógrafo, data el poema "Caracola" de $1926^{1}$, es decir, que fue escrito poco antes de que aparecieran las Cancionesy - como todo el libro- mientras García Lorca vivía en la Residencia de Estudiantes de M adrid². Ello explica el propósito del poeta de expresar, en consonancia con el espíritu lúdico que animaba a los residentes, "bajo el signo de la cancioncilla popular de Lope de Vega, el aspecto risueño, juguetón y burlesco de su personalidad" (Gibson, ${ }^{3} 1987:$ 378).

La dedicatoria del poema "A Natalita Jiménez" revela ese otro aspecto del carácter de G arcía Lorca. Porque la persona a quien le destina el texto es la hija

'V éase en García Lorca, ${ }^{2} 1989:$ I, 517.

${ }^{2}$ Consúltese Gibson, ${ }^{3} 1987$ : II, 229 ss. 
del director de la Residencia, una de la "serie de pequeñas amigas del poeta" (Gibson, ${ }^{31987: ~ 378) . ~ E l ~ h o m e n a j e ~ n o ~ s o ́ l o ~ e x p l i c i t a ~ e l ~ p r o f u n d o ~ a f e c t o ~ q u e ~}$ sentía Lorca por los niños, sino que igual mente su permanente vinculación con su propia niñez ${ }^{3}$.

Tanto el espíritu lúdico de las Canciones como su sustrato infantil son, pues, la expresión de experiencias cotidianas en que se refleja la personalidad del poe ta. Sin embargo, tras el juego o la levedad - "C anciones es el libro más alado de Lorca”" (G arcía-Posada, en G arcía Lorca, ${ }^{2} 1989$, I: 151 s)- , están invariablemente presentes "las constantes temáticas de siempre, aun cuando veladas o meramente aludidas: la búsqueda infructuosa del amor, el temor a la muerte, la tristeza del poeta ante el enigma del tiempo" (G ibson, ${ }^{31987: ~ I, ~} 378$ s).

G arcía Lorca pertenece a la G eneración poética de 1927, cuyas figuras centrales fueron Jorge Guillén, Gerardo D iego, Rafael Alberti, Dámaso Alonso y Pedro Salinas. "Esos escritores no formaban un mero grupo - afirma D ámaso Alonso-, sino que en ellos se daban las condiciones mínimas de lo que entiendo por generación: coetaneidad, compañerismo, intercambio, reacción similar ante excitantes externos" (Alonso, 1952: 182).

El instante central de la Generación es el año 1927, cuando se celebra con expresiones de entusiasmo y adhesión estética el tricentenario de la muerte de Luis de Góngora. Con referencia a esa fecha, se desarrolla la G eneración en dos períodos: "El primero de ligamiento eintegración en vínculos y miembros (respectivamente), y de relativa homogeneización del concepto de poesía, período que iría de 1920 a 1927; y en el segundo, de 1927 a 1936, los vínculos se van lentamente relajando, y, por lo que toca al concepto mismo de lo poético, se abre aquí, diríamos [que con la aparición del 'demonio político'], una importante herejía" (Alonso, 1952: 185).

El libro Canciones fue concebido bajo el signo de la estética gongorina que García Lorca asociaba con la lección del cubismo por "su realismo conceptual, no imitativo, y su actitud frente a la naturaleza", en la cual no buscaba "las cualidades efectivas de los objetos, sino sus naturales equivalencias plásticas", fijándose solamente en los rasgos esenciales de las cosas" (M aurer, en García Lorca, 1984: I, 22) ${ }^{4}$. Sin embargo, también debe ser considerado como un texto que se gesta en un proceso de transición que el poeta evoca en su conferencia "Sketch de la nueva pintura", pronunciada en octubre de 1928, y cuyo esquema histórico coincide, en gran medida, con el desarrollo artístico del propio García Lorca: "Llega 1926. La lección cubista ya está bien aprendida. Pero un triste

${ }^{3}$ Véase García-Posada, en García Lorca, ${ }^{21989: ~ I, ~} 13$ s.

${ }^{4} \mathrm{~V}$ éase igual mente $\mathrm{H}$ auser, ${ }^{2}$ 1978: 705. 
cerebralismo, un cansado intelectualismo invade a la pintura. (...) ¿A dónde vamos? Vamosal instinto, vamosal acaso, a la inspiración pura, a la fragancia de Io directo. Empiezan a surgir los sobrerreal istas. (...) Se comienza a expresar lo inexpresable. El mar cabe dentro de una naranja ..." (G arcía Lorca, 1984: II, $44 \mathrm{~s})^{5}$.

D esde el punto de vista de su conformación métrica constatamos que "C aracola" es un poema compuesto por una sextilla y dos estribillos que la enmarcan.

La sextilla está conformada por seis versos pentasílabos con rima asonante en los pares y los impares sueltos. I gualmente, destacamos la alternancia de ritmos, detal manera quelos versos impares presentan cláusulas rítmicas dactílicas y los versos pares, cláusulas trocaicas. En la estrofa predomina la vocal abierta 'a', primero, por ser la constituyente exclusiva de la rima asonante 'a-a' y, segundo, por recibir, conjuntamente con las vocales medias ' $e$ ' y ' 0 ', los acentos en los versos pares de la composición. Ello contrasta con el predominio de la vocal media 'o' y la cerrada ' $i$ ' que - a excepción del primer verso- conforma tanto la terminación de los versos impares como la secuencia de las vocales acentuadas en el interior de los versos. El estribillo, finalmente, es un decaślabo trocaico simple con apoyos en las vocales 'a', 'i', 'u', 'a', 'o'.

La alternancia de ritmos dactílicos y trocaicos le da a la estrofa un carácter polirrítmico, concordante con el sentido de los versos, por cuanto evoca tanto el movimiento de las olas del mar como también la sístole y diástole del corazón. Esta pulsación la refuerzan la sucesión de la rima y el complemento rítmico que aporta la armonía vocálica de los versos. No obstante, el sentido rítmico de la estrofa queda definido por la sugerencia de serenidad propia del trocaico y la insinuación de vehemencia inherente al dactílic ${ }^{6}{ }^{6}$, cuya alternancia - reforzada por la rima y la armonía vocálica- se percibe como indicio de una secreta tensión.

El estudio de la sintaxis poética del estribillo revela que estamos en presencia de un enunciado con sujeto gramatical indeterminado. Consecuentemente, el interés se centra en el sujeto de la enunciación, es decir, en quien asume lo dicho, el cual se hace presente mediante el pronombre átono "me". La acción "han traído", realizada por el sujeto indeterminado en beneficio del hablante, se expresa en pretérito perfecto, lo cual significa que se trata de una acción real izada en un "pasado y perfecto que guarda relación con el momento presente"

5En la conferencia "Tres modos de poesía", de febrero de 1930, declara que "la exaltación de Góngora que ha sentido toda la juventud poética española ha correspondido con la madurez del cubismo, pintura de raciocinio puro, austera de color y arabesco, que culminó en el castellanísimo Juan Gris" (García Lorca, 1984, II: 26).

${ }^{6}$ V éase N avarro Tomás, 1973: 15. 
(Gili Gaya, 1961: 159). El sujeto de la enunciación se sitúa con respecto a 'ellos' 0 'ellas' en este presente y se manifiesta como receptor del objeto. El enunciado no es sino un predicado de ese sujeto indeterminado, que realiza una acción cuyo objeto lo expresa el complemento directo "una caracola". El hecho que el sustantivo "caracola" esté determinado por el artículo indefinido "una", lo singulariza en su especie y género.

La sextilla está conformada por dos oraciones de estructuras sintácticas equival entes entre sí. D e esta manera, el primer enunciado, que ocupa los versos 1 y 2 está conformado por el sujeto "un mar de mapa", el verbo en presenteindicativo "canta", el caso complementario dativo "le" cuyo antecedente es "caracola", y el adverbio delugar "dentro". El segundo enunciado, que aparece conformado por los versos 3-6, presenta la misma estructura sintáctica, es decir, la forma verbal "Ilena" conjugada en indicativo presente, el sujeto "mi corazón", dondeel adjetivo posesivo "mi" nos remite otra vez al sujeto de la enunciación, el pronombre reflexivo en función de complemento indirecto "se" cuyo antecedente es "corazón" y, finalmente, el complemento circunstancial "de agua con pececillos de sombra y plata".

Estimamos que este análisis nos permite hacer -entre otras- las siguientes observaciones referidas a la construcción del sentido de "Caracola":

(1) El paralelismo gramatical que se observa entre la estructura sintáctica de los dos enunciados que conforman la sextilla sugiere que también existe una equivalencia semántica entre las partes y la totalidad. Consecuentemente, los procesos "canta" y "Ilena" son tan equivalentes como lo son "mar de mapa" y "corazón".

(2) El hecho que se haya pospuesto el sujeto gramatical "un mar de mapa" a la forma verbal explicita el propósito de destacar el espacio interior de la caracola. Es por eso que el enunciado se inicia con el adverbio "dentro", antepuesto al pronombre "le" que sustituye al sustantivo "caracola".

(3) Las formas verbales "canta" y "Ilena" denotan ambas acciones que coexisten con el sujeto gramatical. Ello explica que sus respectivos objetos "le" (caracola) y "se" (corazón) terminen confundidos con sus respectivos sujetos, es decir, "caracola" con "un mar de mapa" y "mi corazón" consigo mismo en un proceso en el cual el sujeto de la enunciación es a la vez agente y paciente de la acción.

(4) El adverbio "dentro" significa "en el interior de un espacio real o imaginario" (RAE, 1992: I, s.v.). Su equivalente es el complemento circunstancial "de agua con pececillos de sombra y plata". La relación entre ambos es de interioridad continentea materia contenida, y su paralelismo sintáctico refuerza la equivalencia semántica entre los espacios continentes caracola y corazón. 
La estructura de la significación del poema se conforma, fundamentalmente, a partir de la connotación, los tropos y la intertextualidad.

El texto lleva por título el nombre "caracola", término que la Real Academia Española define como "la concha de un caracol marino de gran tamaño, de forma cónica". Se trata, pues, de un sustantivo concreto sintácticamente indeterminado, por lo cual adquiere cierto sentido abstracto o general que nos advierte sobreel carácter simbólico de la composición. En los estribillos se le antepone el artículo indeterminado "una" al sustantivo "caracola", lo cual sugiere que el interlocutor puede pensar en cualquier unidad de la especie nombrada. El sentido de la caracola se va precisando en la medida que avanza el desarrollo del poema.

El primer tropo con que nos encontramos una vez iniciada la lectura del texto es la imagen personificada "un mar de mapa", en alusión tanto a la reducida dimensión como a la percepción humanizada del mar que "canta" dentro de la caracola. Consecuentemente, en la lógica del poema, se nos habla, luego, del "agua" habitada por los "pececillos de sombra y plata", que "Ilena" el "corazón" del sujeto de la enunciación.

En el poema "C aracola", el "mar" se transforma en "agua" cuando penetra en el "corazón". Esta relación entre "mar" y "corazón" nos recuerda que entre los místicos "el mar simboliza el mundo y el corazón humano en cuanto sede de las pasiones". I gualmente, hay que tener presente que el "mar" es considerado, tradicionalmente, como el "símbolo de la dinámica de la vida", y que por sus aguas en movimiento simboliza "una situación de ambivalencia que le da la incertidumbre", lo cual explica que "el mar sea a la vez símbolo de la vida y de la muerte" (Chevalier/G heerbrant, ${ }^{6} 1999$ : s.v.). Por otra parte, el mar suele expresar, en la obra de G arcía Lorca - como, por ejemplo en el "Romance de la pena negra" (1989: 2, 154-155)-, el fracaso de la pasión y el amor:

\section{No me recuerdes el mar que la pena negra brota en las tierras de aceituna bajo el rumor de las hojas}

El sentido de la imagen (o comparación per brevietatem) "pececillos de sombra y plata" se constituye en función del color. Es así como el color metálico, frío de la plata adquiere en la obra de García Lorca "el valor de punzante(s) y doloroso(s) símbolo(s) de la muerte" (Xirau, en Gil, 1973: 209) -las navajas "relucen como peces" en el Romancero gi tano (García Lorca, ${ }^{2} 1989$, II: 145)- y 
"el negro y su encarnación en la sombra" funcionan como "expresión y símbolo de la pena, del pozo oscuro, de la noche, de la soledad y la muerte" (Sabugo, 1986: 483). $\mathrm{H}$ ay que notar quetodas estas significaciones especifican el sentido simbólico de "pececillos" - ya anunciado por el carácter abstracto y general que adquiere el sustantivo concreto por su indeterminación sintáctica- tradicionalmente asociado a la vida en su expresión puramente sensual y de pasión amorosa, y que en la obra de G arcía Lorca suele aparecer también en "metáforas de índole cósmica, principalmente en relación con el estado cambiante de sombra a luz a la hora de la madrugada" (C orrea, 1957: 51).

No cabe duda que "se llena de agua" está empleado connotativamente, ya que lo propio del corazón es colmarse de sangre. Se trata de una connotación metonímica, por cuanto como lympha, 'agua', pertenece a la parte líquida de la sangre, en la cual desempeña por excelencia la función de elemento vital. Sin embargo, también hay que considerar, primero, queel agua simboliza "la infinidad de lo posible", porque contiene "todas las promesas de desarrollo, pero también todas las amenazas de reabsorción" (C hevalier/G heerbrant, " $1999:$ S.V.), segundo, que esa indeterminación debemos leerla con relación a los "pececillos de sombra y plata" que, en cuanto complemento del nombre, completa su significación y, tercero, queel agua es concebida en la obra de G arcía Lorca, gracias a su capacidad especular y difluyente, como elemento que interrelaciona lo remoto con lo cercano, lo inmenso con lo mínimo, lo natural con lo humano, lo universal con lo particular8.

Paul Ricoeur afirma que "existesímbolo cuando la lengua produce signos de grado compuesto en los que el sentido, no bastándole designar a un objeto cualquiera, designa otro sentido que no podría ser alcanzado sino en y por esa traslación" (1965: 25). En consecuencia, una palabra, una frase o todo un texto deviene símbolo cuando a su significación primaria se le asocian significados secundarios sólo accesibles a través de la significación primaria: "la significación primaria aporta a la secundaria como el sentido de un sentido" (Ricoeur, 1995: 68).

H ablamos de símbolos convencionales cuando han sido consagrados por la tradición cultural, y de símbolos contingentes cuando son propios y específicos de la obra de un poeta que los ha descubierto -como en el caso de "Caracola"en al guna circunstancia particular. La característica fundamental del símbolo es su polivalencia que deviene tanto de las diversas cualidades del objeto que le

${ }^{8}$ éase el estudio de Concha Zardoya, "Los espejos de Federico García Lorca", en Gil, 21973: 237 SS. 
sirve de soporte como de la interrelación que establece con otros símbolos, sin importar su origen contingente 0 tradicional ${ }^{9}$.

Los dos elementos que interrelaciona el agua son "caracola" y "corazón", este último como símbolo del centro vital, afectivo e intelectual del ser humano, y cuyo "doble movimiento (sístole y diástole) hacen [del corazón] también el símbolo del doblemovimiento de expansión y reabsorción del universo" (C hevalier) G heerbrant, ${ }^{6} 1999:$ s. v.). En plena concordancia con esa intelección de "corazón", se comprende "caracola" como símbolo de "las dialécticas de lo grande y de lo pequeño, de lo ocul to y de lo manifiesto", como "piedra habitada" y expresión de topofilia hacia espacios que "concentran ser en el interior de los límites que protegen" y que en virtud de ese valor protector "adhieren también valores imaginados [que] son muy pronto valores dominantes" (Bachelard, 1965: 29 y cp. V).

La intertextualidad designa el hecho quetodo texto se hace en la reminiscencia y metamorfosis de otros textos. Esta actividad que se denomina trabajo intertextual puede adoptar diversas formas que definen las transformaciones de un texto en el proceso intertextual. U na de esas formas es la amplificación que indica la mutación deun texto referentegracias al desarrollo de sus virtualidades semánticas ${ }^{10}$.

Evocamosal respecto el poema "N o sési el mar..." , de uan R amón Jiménez, incluido en el Diario de un poeta, y escrito en junio de 1916.

NO SÉ SI EL MAR ...

No sé si el mar es, hoy

- adornado su azul de innumerables

espumas-,

mi corazón; si mi corazón, hoy

- adornada su grana de incontables

espumas-

es el mar.

Entran, salen

uno de otro, plenos e infinitos,

como dos todos únicos.

A veces, meahoga el mar el corazón, hasta los ciel os mismos.

M i corazón ahoga el mar, a veces,

hasta los mismos ciel os.

${ }^{9}$ C onsúltese M orier, ${ }^{3} 1981$ : s.v.

${ }^{10} \mathrm{~V}$ éase Jenny, 1976: 257 ss. 
Esta referencia a Juan Ramón no es casual, sino se fundamenta en su especial relación con G arcía Lorca y su evidente filiación con la G eneración de 192711. Es por eso que postulamos la existencia de un vínculo de reminiscencia entre "No sé si el mar..." y "C aracola", que se define como un proceso de amplificación textual.

Aun cuando nos limitemos a la primera lectura del texto, podemos observar queambos poemas se constituyen en la dialéctica de lo natural/universal simbolizado por el mar y lo humano/particular e íntimo simbolizado por el corazón. Sin embargo, mientras Juan Ramón busca transcribir el efecto afectivo de esa experiencia, G arcía Lorca intenta dar cuenta que "Io 'uno' es 'todo' (...) porque una esencia común - ser en el cosmos- los habita einforma" (Concha Zardoya, en Gil, 1973: 246). Consecuentemente, persigue el propósito de construir una realidad poética en la cual "el sí y el no de las cosas son igualmente verdaderas" (García Lorca, en M aurer, 1984; I, 153), "todo se halla en viva fusión" y "Io concreto (...) se amplifica hasta lo cósmico, lo abstracto y lo mágico" (C oncha Zardoya, 1961: 366 y 368) ${ }^{12}$. Es por eso que García Lorca define su proyecto poético-existencial de la manera siguiente:

Por la vereda azul, domador de sombrías estrellas, seguiré mi camino.

H asta que el Universo quepa en mi corazón. ${ }^{13}$

Los procedimientos para dar cuenta de esa presencia del todo en cada una de sus partes son "las imágenes intervalentes y plurivalentes [que] constituyen el fenómeno metafórico más continuo y constante en toda la obra lorquiana". En ella "cada elemento de lo creado se traffundeen otro, aunque pertenezca al plano más alejado. 0 se dispara, se irradia o se superpone" (Concha Zardoya, 1961: 368).

La poesía de Juan Ramón Jiménez es una "lírica (...) de reflejos, del poeta reflejándose, reflexionándose" (Salinas, 1961: 323) en la realidad. Estimamos que ello se evidencia al examinar el desarrollo de "N o sési el mar...", queprime-

${ }^{11}$ Consúltese Alonso, 1952: 174 y G ibson, ${ }^{31987: ~ I, ~} 381$ ss.

${ }^{12}$ Allen W. Phillips describe el proceso de creación poética de nuestro poeta en los términos siguientes: "U nainsistente predilección por la poetización de lo minúsculo caracteriza la poesía de Lorca. Se deleita con ternura en los pequeños motivos naturales, infantiles, populares 0 tradicionales. Arranca de una realidad cualquiera (lostestimonios son frecuentes sobrelasfuentes de ciertos poemas y obras de teatro); la ve en todos sus detalles y relacionada con la realidad total de que es parte; y la eleva a la categoría universal y mítica" (1958: 46).

${ }^{13}$ G arcía Lorca, “Curva”, en: Suites, Poesía, 1, 0 brasl. Ed Akal, M adrid, 1989, p. 387 s. 
ro evoca el encuentro entre el "mar" y el "corazón" del poeta en términos de (con)fusión (vv 1, 4 y 7), plena correspondencia (vv 2-3 y 5-6) y pulsación (v 8-10), y queluego recuerda el efecto opresor de lo inconmensurable ala vez que la sensación de posicionamiento cuando se expande hasta la infinitud (vv 1314). Sugerimos, en consecuencia, que el ahogo mencionado en los versos 11 y 13 puede leerse tanto como expresión del terror que se siente ante lo infinito como de la exaltación que se experimenta en el proceso de expansión hasta la inmensidad.

D iferente es la poesía de G arcía Lorca en esta etapa de su desarrollo desde el cubismo hacia el surrealismo. Porque si aquél se caracteriza por "el predominio (...) de la realidad intelectual sobre la realidad sensorial" (De Torre, 1971: I, 238), y éste reposa "en la creencia en la realidad superior de ciertas formas de asociación hasta ahora desdeñadas, en la omnipotencia del sueño, en el juego desinteresado del pensamiento" (Breton, Primer manifiesto surrealista), el anhelo de Lorca es "penetrar en la natural eza, entender su lenguaje (...) con el afán de unirseal resto dela creación" (M aurer, en G arcía Lorca, 1984: I, 22 s). Espor eso que se vale, en esta fase de su evolución poética, de las concepciones y procedimientos de ambos movimientos literarios, y los pone al servicio de su propósito de formar parte de la naturaleza, acaso en un impulso dionisiaco que "penetra en los pensamientos más íntimos de la naturaleza, [donde] conoce el terrible instinto de vivir y a la vez la incesante muerte de todo lo que comienza a existir" (N ietzsche, 1995: 239).

En una breve recapitulación de estas observaciones que, por cierto, no agotan el tema, proponemos el siguiente cuadro resumen dela relación intertextual entre los poemas comentados.

\begin{tabular}{|l|l|}
\hline \multicolumn{1}{|c|}{ "No sé si el mar" } & \multicolumn{1}{c|}{ "Caracola" } \\
\hline $\begin{array}{l}\text { Sensaciones de correspondencia } \\
\text { entre el temple de ánimo } \\
\text { (Stimmung) y la naturaleza }\end{array}$ & $\begin{array}{l}\text { Percepciones de totalidad en las partes } \\
\text { de todos los ámbitos, sean ellos } \\
\text { humanos o naturales }\end{array}$ \\
\hline $\begin{array}{l}\text { Construcción de formas } \\
\text { correlativas y correspondientes }\end{array}$ & $\begin{array}{l}\text { Montaje de elementos inter- y } \\
\text { plurival entes }\end{array}$ \\
\hline $\begin{array}{l}\text { En el reflejo anímico, superación } \\
\text { de la diferencia entre lo humano } \\
\text { y lo natural }\end{array}$ & $\begin{array}{l}\text { En la unidad universal, superación de la } \\
\text { diferencia entre lo humano y lo natural }\end{array}$ \\
\hline $\begin{array}{l}\text { Correspondencia entre la parte y } \\
\text { la totalidad }\end{array}$ & Presencia del todo en las partes \\
\hline
\end{tabular}


Finalmente, dos aclaraciones necesarias sobre este cuadro y la antes postulada amplificación del texto referente de Juan Ramón Jiménez en el poema de García Lorca:

(1) Es obvio que también encontramos conformaciones correlativas en "Caracola". No obstante, dominan las figuras inter- y plurivalentes en la composición. Es gracias a ellas que el poema pueda plantearse desde las partes en términos de totalidad.

(2) Consecuentemente, se produce una amplificación semántica de un texto a otro, porque las sensaciones específicas de correspondencia entre el temple deánimo y la natural eza que caracteriza el poema de Juan Ramón, son llevadas en la composición de Lorca al plano superior de la correlación universal entre las partes que conforman la totalidad.

Sin duda es difícil proponer una explicación histórica, cultural y social de un solo poema que, como "Caracola", se constituye a primera vista en una -en palabras de Ferrater- "interpretación de la ocasión cotidiana". N o obstante, en algo nos ayuda en este propósito la certeza de que fuera escrito en 1926, que es en la concepción de G arcía Lorca el año-gozne dela transición desdeel cubismo al surreal ismo. Consecuentemente-y al go ya vimos de ello-, el poema participa en su conformación de ambos movimientos, del primero por la fragmentación analítica de sus elementos provenientes, cada uno, de diferentes esferas de la realidad real, de ambos, por la yuxtaposición y el montaje de sus componentes, y del segundo, por la creación de una realidad poética que transluce totalidad ${ }^{14}$.

"Caracola" es, pues, una expresión poética propiamente moderna, "postimpresionista", en la terminología de Arnold H auser (1962: II, 398 y /1978: 705), concebido más allá del principio mimético dela reproducción de la naturaleza. García Lorca identifica este rechazo de la afirmación e identificación artística de la realidad con las consecuencias de la Primera Guerra M undial. "Año 1914. La gran guerra destruye la realidad real. Lo que se ve es incréble. $\mathrm{N}$ o hay razonamiento que resista la guerra. Lo visible no parece auténtico. Las construcciones éticas se vienen abajo. Lo que creíamos ya no lo creemos. Se rompen todas las cadenas y el alma sin asidero se encuentra sola, desnuda, dueña de su perspectiva. No hay que hacer caso de los ojos que engañan. $H$ ay que libertarnos de la realidad natural" (1984: II, 40).

14“ La experiencia básica de los surrealistas consiste en el descubrimiento de una segunda realidad, que, aunque está inseparablemente fundida con la realidad ordinaria y empírica, es, sin embargo, tan diferente a ella que sólo podemos hacer aserciones negativas sobre ella y referirnos a los vanos y huecos en nuestra experiencia como prueba de que existe" (H auser, 1962: II, 403). 
No cabe duda quela fragmentación y el montajeque señalamos en "C aracoIa" como indicios de su pertenencia cubista y surrealista, son también síntomas de la ruptura y dispersión de la realidad y, consecuentemente, de las visiones ética y conceptual que se tuvo de ella.

El anhelo de totalidad, tan propio de la poesía de la época ${ }^{15}$, es, pues, indicio y respuesta a la carencia que siente el poeta ante la destrucción de la realidad real, dispersión y aislamiento del hombre y ruptura de una visión unitaria del mundo. "El alma sin asidero se encuentra sola", escribe Lorca, de dondeel deseo de "poner unidad y coherencia, por cierto de un modo muy paradójico, en el mundo atomizado en que vivimos" (H auser, 1962: II, 405). En esa realidad fragmentada, dispersa y múltiple, el alma se convierte en "dueña de su perspectiva", y el poeta se vale de ella para construir poemas que en el montaje de elementos disímiles conforma una estructura estética no imitativa que transparenta una segunda realidad, no parcial ni fragmentada, sino total.

Sin embargo, el poema en cuanto "mundo que conmueve o hace pensar", que "define (...), fija y orienta la emoción" (G arcía Lorca, 1984: II , 42), junto con constituirse en la "pre-apariencia estética"16 de la totalidad perdida, es una permanente apelación al lector para participar activamenteen su (re)constitución. Son portadores de ese llamado, por una parte, el potencial de sentido ofrecido por las imágenes inter- y polivalentes y, por otra, los puntos de interconexión entre esas imágenes que, por carecer de motivación explícita, son verdaderos lugares vacíos ${ }^{17}$ que incitan a participar en constitución del sentido ausente EI lector realiza estas dos funciones de elección e institución de sentido para el poema, pre-orientado por la perspectiva espacio-temporal del yo lírico, quehace suya por cuanto carece de lo que Benveniste denomina la "referente actual", y de acuerdo con "Ios condicionamientos históricos, sociales e individuales, dentro de los que se mueve el receptor del texto" (Acosta Gómez, 1989: 171).

El lector - sostenemos- forma parte de una realidad social en la cual todo se halla definido de antemano, que lo ha transformado en un accidente prescindibley quese encuentra dominada por el principio deutilidad. Por el contrario, el poema lo involucra en una realidad estética que requiere de su aporte para cons-

${ }^{15}$ V éase H auser, ${ }^{2} 1978: 743$.

${ }^{16}$ Según Ernst Bloch - en palabras de osé Jiménez- "el arteopera con la realidad sensible, la creatividad que transporta se apoya, siempre, en una acción estética inmanente. Pero el arte no se queda, sin embargo, en la mera apariencia e ilusión. Al manipular la realidad sensible, los material es del mundo, va más allá de la apariencia, en sus líneas se dibuja una preconfiguración o pre-apariencia (Vor-Schein) de algo que no existe todavía, y que, a pesar de ello, puede llegar a ser" (Jiménez, 1993: 75). V éase también Bloch, 1969: 58 ss.

${ }^{17}$ Para la aplicación del concepto de lugar vacío (I ser, 1971, en Rall, 1993: 99 ss) a la lírica véase Spinner, 1975: 17 s. 
tituirse, y cuyo sentido se gesta en un proceso solidario, a través del cual el lector se re-encuentra con la experiencia de su esencial independencia y libertad.

La relación entre el texto y el contexto histórico, cultural y social, se vuelve evidente en estos procedimientos artísticos: el Ilamado a la participación del lector, la pre-apariencia estética de la totalidad ausente y el rechazo de la imitación de la realidad. Consecuentemente, "Caracola" se nos presenta como un mundo en gestación, cuya realización - entre infinitas opciones- queda entregada a la libre actividad creativa, comprensiva y crítica del lector.

Una rápida revisión de los resultados obtenidos en las diferentes fases de nuestro comentario nos lleva a la conclusión que estamos en presencia de un poema que trabaja por constituirse en un símbolo de totalidad. Consecuentemente, todos los niveles de la composición concurren para construir una realidad de esferas interrelacionadas, intervalentes e interdependientes.

La alternancia de ritmos envuelve a corazón y caracola en una dinámica de expansión y recogimiento, también presentes en el amor, la muerte, la esperanza y la desilusión. Es por eso que se disuelven los límites y la naturaleza y el hombre, lo material y lo espiritual, la circunstancia y el cosmos se integran y participan de una misma pulsación universal.

La técnica para lograr esa expresión de totalidad es la del montaje de planos, es decir, la combinación de realidades heterogéneas para mostrar no sólo fenómenos interrelacionados sino explicitar su fundamental unidad. La utilización de este procedimiento como medio para develar en la realidad empírica la presencia de otra realidad diferente, y para crear con ellos un equivalente poético, es decir, una obra que no fuera su reflejo sino que se bastara a sí mi sma, demuestra el carácter transitivo entre cubista y surrealista de la composición.

\section{REFERENCIAS}

Acosta Gómez, LuisA. 1989. El lector y la obra. Teoría dela recepción literaria. Ed. Gredos, Madrid.

Alonso, D ámaso. 1952. “Una generación poética (1920-1936)", en: Poetas españoles contemporáneos. Ed. Gredos, M adrid.

Bachelard. 1965. La poética del espacio. FCE: Breviarios N 13, M éxico.

Benveniste, Emile. ${ }^{8} 1979$. "D e la subjetividad en el lenguaje", en: Problemas delingüística II. Siglo Veintiuno Editores, M éxico, pp. 179 ss.

Bloch, Ernst. 1969. D as Prinzip H offnung I-III. Suhrkamp Verlag, Frankfurt am M ain. Breton, André. 1965. L os manifiestos del surrealismo. Ediciones NuevaVisión, BuenosAires. Correa, Gustavo. 1957. La poesía mítica de Federico García Lorca. University of Pregon Publications, Eugene, 0 regon.

Chevalier, Jean / G heerbrant, Alain. ${ }^{6} 1999$. D iccionario de losśmbolos. Ed. Herder, Barcelona. De Torre, Guillermo de. 1971. H istoria de las literaturas de vanguardia I - III. Ed. Guadarrama, M adrid. 
García Lorca, Federico. 1950. Cartasa sus ami gos. Ediciones C obalto, Barcelona.

- 1965. O bras completas. Ed. Aguilar, M adrid.

1984. Conferencias. 2 tomos. Alianza Editorial, M adrid.

- Poesía 1 y Poeśa 2. O bras I y O bras II. Ediciones Akal, M adrid.

G arcía-Posada, M iguel. "Introducción general" e "Introducción”, en: G arcía Lorca ${ }^{21989:}$ I, 11 ss y II, 7 ss

Gasch, Sebastián. "Prólogo”, en: García Lorca, 1950.

Gibson, Jan. ${ }^{3} 1987$. Federico García L orca I - II . Ediciones G rijalbo, Barcelona.

Gil, Idelfonso M anuel (ed.). 1973. Federico García Lorca. Editorial Taurus, M adrid.

Gili Gaya, Samuel. ${ }^{8} 1961$. Curso superior de sintaxis española. Publicaciones y Ediciones SPES, Barcelona.

Guillén, Jorge. "Prólogo", en García Lorca ${ }^{8} 1965$ : XVII ss.

$\mathrm{H}$ auser, Arnold. 1962. H istoria social dela literatura y el artel y II. Ediciones Guadarrama, M adrid.

--_------. 21978. Soziologie der Kunst. Beck'sche Verlagsbuchhandlung, M ünchen.

I ser, Wolfgang. "La estructura apelativa de los textos", en: Rall, 1993: 99 ss.

Jakobson, Roman. 1973. "Poésie dela grammaireet grammaire dela poésie", en: Q u estions de poétique. Ed. du Seuil, Paris, pp. 219 ss.

Jenny, Laurent. 1976. "La stratégie de la forme”, en: Poétique, 27, Paris, pp. 257 ss.

Jiménez, José. 1993. "Ernst Bloch: teoría dela preapariencia estética” en: Anthropos. Revista de documentación científica de la cultura, 146/147, Barcelona, julio-agosto, pp. 74 ss. Jiménez, Juan Ramón. 1952. Libros de poeśa. Ed. Aguilar, M adrid.

Lázaro C arreter, Fernando. ${ }^{3} 1968$. D iccionario detérminosfilológi cos. Ed. G redos, M adrid. M aurer, Christopher. "Introducción", en: García Lorca 1984: I.

M orier, Charles. ${ }^{3}$ 1981: D ictionnaire de Poétique et de Rhétorique. PU F, Paris.

N avarro Tomás, Tomás. 1973. Los poetas en sus versos desde Jorge M anriquea García Lorca.

Ediciones Ariel, Barcelona.

N ietzsche, Federico. 1995. El nacimiento de la tragedia. Alianza Editorial, M adrid.

Phillips, Allen W. 1958. "Sobrela poética de G arcía Lorca", en: Revista H ispánica M oderna, XXIV, 1, N ueva York, pp. 36 ss.

Rall, D ietrich (comp.). 1993. En busca del texto. Teoría de la recepción literaria. U N AM, M éxico.

Real Academia Española. ${ }^{21} 1992$. D iccionario de L engua española I - II. Ed. Espasa-Calpe, M adrid.

Ricoeur, Paul. 1965. D el'interpretation. Ed. du Seuil, Paris.

-.-_-_-- . 1995. Teoría de la interpretación. Discurso y excedente de sentido. Siglo XXI Editores, M éxico.

Sabugo Abril, Amancio. 1986. "Claves interiores de la poesía lorquiana”, en: Cuadernos H ispanoamericanos, 435-36, septiembre-octubre, M adrid, pp. 479 ss.

Salinas, Pedro. 1961: "García Lorca y la cultura de la muerte", en: Ensayos de literatura hispánica. (D el Cantar de M ío Cid a García Lorca). Ed. Aguilar, M adrid, pp. 374 ss.

Spinner, Kaspar H . 1975. Zur Struktur des lyrischen Ich. Akademische Verlagsgesellschft, Frankfurt am M ain.

Xirau, Ramón. "La relación metal-muerte en los poemas de García Lorca”, en: Gil 1973: pp. 207 ss.

Zardoya, Concha. “Los espejos de G arcía Lorca”, en: Gil, 1973. 